\title{
Managing polypharmacy in a 77-year-old woman with multiple prescribers
}

\author{
Barbara Farrell BScPhm PharmD, Véronique French Merkley MD, Wade Thompson HBSc
}

Competing interests: See end of article.

This article has been peer reviewed.

Correspondence to: bfarrell@bruyere.org

CMAJ 2013. DOI:10.1503 /cmaj.122012
This article is one of several prepared as part of a collaboration between the Geriatric Day Hospital of Bruyère Continuing Care, CMAJ, Canadian Family Physician and the Canadian Pharmacists Journal to assist clinicians in the prevention and management of polypharmacy when caring for older patients in their practices.

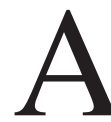
77-year-old woman was referred to a geriatric day hospital with concerns about mobility and falls, pain, constipation, cognition and polypharmacy. Comorbidities included cerebrovascular disease, coronary artery disease, hypertension, dementia, fibromyalgia, myositis, bipolar disorder, arthritis, remote duodenal ulcer and hypothyroidism. A stroke 3 years earlier resulted in increasing difficulties with transfers and ambulation, leading to 3-4 falls weekly. Chronic pain was attributed to fibromyalgia. The patient was frustrated by her loss of independence, because she now required daily assistance with washing and dressing. Staff at her retirement residence managed her complex medication regimen (see Box 1 for the list of medications). Placement in a long-term care facility was being considered.

At presentation, the patient was wheelchairbound and heavily sedated, which made the interview and assessment difficult. She had had

\section{KEY POINTS}

- Medications are potential contributors to geriatric syndromes such as falls and cognitive impairment.

- The risk of falls can be increased with certain drug classes such as antihypertensives, central nervous system depressants and cardiovascular agents.

- Drugs with anticholinergic properties can have additive effects, with the result being a high anticholinergic load.

- Different classes of medications can be successfully stopped concomitantly; careful planning is required to avoid and monitor for adverse events related to drug withdrawal.

- Communication between health care professionals will improve medication selection and avoid doses that contribute to functional difficulties in older patients. near-falls while attempting to transfer herself from her wheelchair and was unable to stand unsupported. Orthostatic hypotension was noted (drop in blood pressure from 118/64 mm Hg while reclining to $80 / 50 \mathrm{~mm} \mathrm{Hg}$ after standing).

The patient accepted a 12-week admission to the geriatric day hospital, and twice-weekly transportation was organized. A multidisciplinary team, including a pharmacist, a nurse, a social worker, an occupational therapist and a physiotherapist, was consulted. Results of bloodwork were normal except for a low calcium level (2.17 [normal 2.20-2.65] mmol/L). Using the Cockcroft-Gault equation with ideal body weight, we calculated her creatinine clearance to be $30 \mathrm{~mL} / \mathrm{min}$, which we considered to be low for her age.

Initial visits led to the development of an interprofessional plan. The pharmacist assessed the medication list, evaluating each medication for indication, effectiveness, safety, compliance and patient understanding. ${ }^{1}$ The patient's personal experience with medications was difficult to ascertain because of her sedation. Results of the initial medication assessment are outlined in Appendix 1 (available at www.cmaj.ca/lookup /suppl/doi:10.1503/cmaj.122012/-/DC1). Signs and symptoms were assessed to identify drugrelated causes. ${ }^{2}$ The complete medication assessment is outlined in Box 2.

Throughout the admission, several medication changes were made (Appendix 2, available at www.cmaj.ca/lookup/suppl/doi:10.1503/cmaj $.122012 /-/ D C 1)$. The patient participated in physiotherapy and exercise to address deconditioning. The occupational therapist reviewed daily activities and fall-prevention strategies. The patient's leg strength and balance improved (her Berg Balance score increased from 18 to 31 out of 56). She progressed from using a wheelchair to walking $150 \mathrm{~m}$ with a cane. No falls were reported from the fourth week of admission onward.

Despite a reduction in her analgesic medica- 
tions, her pain did not worsen, in part because nonpharmacologic coping strategies were used. She reported having increased self-confidence and independence in daily activities. Her constipation resolved. She became much more alert and resumed old hobbies such as knitting. The social worker provided supportive counselling sessions, and the patient incorporated relaxation strategies into her daily routine. The patient's mobility and cognition improved, and she sought opportunities to interact with other patients and participate in activities. She reported improved nighttime sleeping and no more daytime napping. Once medications affecting cognition were minimized, a reassessment with neuropsychology ultimately showed findings in keeping with the size and location of her stroke, but no dementia.

The patient's daily pill burden decreased from 32 to 17 pills by the end of the 12-week admission. A final medication list is presented in Box 3. A recommendation was sent to her neurologist requesting reassessment of galantamine; at followup 1 year later, the drug was no longer being taken.

\section{Discussion}

When multiple prescribers are involved in caring for a patient with several chronic diseases, the number of medications can quickly accumulate. Family physicians may be reluctant to modify or stop medications prescribed by consultants or started in hospital. ${ }^{4}$ No one person may have an overall view of how the combination of medications affects the patient, and subsequent negative additive effects may go unnoticed and unmanaged. Figure 1 illustrates the interplay between the patient's medications and the possible effects on sedation, cognition, constipation and risk of falls.

\section{Anticholinergic load}

Anticholinergic load, characterized by the cumulative effect of drugs with anticholinergic properties, can result in sedation, cognitive dysfunction, unsteadiness, orthostatic hypotension, tachycardia, dry mouth, constipation and vision problems. Ultimately, the risk of falls increases and function is impaired..$^{5-11}$ This problem is especially important in older people because there is an age-related increase in the risk of anticholinergic toxicity owing to a decline in cholinergic transmission and increased permeability of the blood-brain barrier. ${ }^{12}$

With polypharmacy so prevalent in the older population, it is not surprising that an older patient could be taking several anticholinergic medications that contribute to or worsen the presentation of geriatric syndromes such as con- fusion and falls. In our patient's situation, several of her medications (amitriptyline, carbamazepine and cyclobenzaprine) are medium to highly anticholinergic, whereas others (diltiazem, furosemide, morphine and oxazepam) are mildly anticholinergic. ${ }^{13}$ The contribution of these drugs to the patient's symptoms is shown in Box 2, and interventions to reduce the anticholinergic load are outlined in Appendix 2.

\section{Additive CNS depression}

As noted in Figure 1, the combination of multiple psychoactive agents likely contributed to poor balance, falls, sedation and impaired cognition in our patient. Individually and in combination, tricyclic antidepressants, muscle relaxants, benzodiazepines,

\begin{tabular}{|c|c|}
\hline \multicolumn{2}{|l|}{ Box 1: Initial list of medications } \\
\hline Medication, dosage & Reason for use, if known \\
\hline Quinapril 40 mg/d & CAD/hypertension \\
\hline Amlodipine $5 \mathrm{mg} / \mathrm{d}$ & CAD/hypertension \\
\hline Diltiazem ER 360 mg/d & CAD/hypertension/angina \\
\hline Acebutolol $200 \mathrm{mg}$ twice daily & CAD/hypertension/angina \\
\hline Nitroglycerin patch $0.6 \mathrm{mg} / \mathrm{h}$ at bedtime & CAD/angina \\
\hline Nitroglycerin spray $0.4 \mathrm{mg} / \mathrm{spray}$ as needed & CAD/angina \\
\hline Furosemide $40 \mathrm{mg} / \mathrm{d}$ & Edema \\
\hline Dipyridamole/ASA 200/25 mg twice daily & Stroke in 2008 \\
\hline Rosuvastatin 20 mg twice daily & Stroke in 2008 \\
\hline Levothyroxine $0.088 \mathrm{mg} / \mathrm{d}$ & Thyroid ablation \\
\hline Tiotropium $18 \mu \mathrm{g} / \mathrm{d}$ & Unclear if COPD or asthma \\
\hline $\begin{array}{l}\text { Salbutamol } 100 \mu \mathrm{g} / \text { puff, } 2 \text { puffs four } \\
\text { times daily if needed }\end{array}$ & Unclear \\
\hline Galantamine ER 16 mg/d & Dementia \\
\hline Morphine $10 \mathrm{mg}$ at bedtime & Pain (fibromyalgia) \\
\hline $\begin{array}{l}\text { Acetaminophen } 650 \mathrm{mg} \text { every } 4-6 \mathrm{~h} \\
\text { as needed }\end{array}$ & Pain (fibromyalgia) \\
\hline Cyclobenzaprine $5 \mathrm{mg}$ three times daily & Pain (fibromyalgia) \\
\hline Glucosamine 500 mg twice daily & Pain (type of arthritis unclear) \\
\hline Amitriptyline $75 \mathrm{mg}$ at bedtime & Insomnia \\
\hline Oxazepam $15 \mathrm{mg}$ at bedtime & Insomnia \\
\hline Lactulose $15 \mathrm{~mL} / \mathrm{d}$ as needed & Constipation \\
\hline $\begin{array}{l}\text { Magnesium hydroxide } 311 \mathrm{mg}, 1-2 \text { tablets } \\
\text { at bedtime }\end{array}$ & Constipation \\
\hline Fibre in water & Constipation \\
\hline Bisacodyl, 2 pills as needed & Constipation \\
\hline Suppository? & Constipation \\
\hline Cranberry $500 \mathrm{mg}$ three times daily & Bladder \\
\hline Carbamazepine 200 mg twice daily & Post-stroke seizure prophylaxis \\
\hline Omeprazole 20 mg/d & History of duodenal ulcer \\
\hline Levofloxacin $250 \mathrm{mg} / \mathrm{d}$ & Urinary tract infection \\
\hline
\end{tabular}




\section{Box 2: Complete assessment of medications for potential drug-related problems and resulting medication care plan}

\begin{tabular}{l}
\hline Potential drug-related problem \\
\hline Low blood pressure and orthostatic hypotension \\
(and frequent falls) \\
- May be contributed to by cardiovascular \\
medications: \\
- Nitroglycerin patch \\
- Furosemide \\
- Amlodipine \\
- Acebutolol \\
- Quinapril \\
- Diltiazem
\end{tabular}

Orthostatic hypotension, poor balance, excessive sedation and frequent falls

- May be contributed to by anticholinergic load:

- Amitriptyline

- Cyclobenzaprine

- Morphine

- Carbamazepine (not likely required for post-stroke seizure prophylaxis; may have drug accumulation owing to inhibition of cytochrome P450 3A4 enzyme by diltiazem and omeprazole)

- Oxazepam (diltiazem and furosemide considered above)

Reduced cognition

- May be contributed to by anticholinergic load and CNS depressants (diltiazem, furosemide, amitriptyline, cyclobenzaprine,

carbamazepine, morphine, oxazepam)

- May not require treatment with galantamine once medication contributors tapered

Constipation (stools infrequent, straining)

- May be contributed to by anticholinergic load (plus other mechanisms for diltiazem and morphine)

- Requires alternate treatment, because patient is not using current regimen successfully

Risk of hypermagnesemia and associated toxicity (e.g., hypotension and cramps)

- May be contributed to by magnesium therapy given reduced renal function (creatinine clearance $30 \mathrm{~mL} / \mathrm{min}$ )

1. Immediate:

- Stop nitroglycerin patch

- Decrease furosemide to $20 \mathrm{mg} / \mathrm{d}$

- Stop amlodipine

2. 1 wk later: decrease acebutolol to $100 \mathrm{mg}$ twice daily; consider further decrease in future

3. Future: if needed, consider reducing quinapril, because current daily dose is at maximum

4. Future: consider reducing diltiazem ER to $240 \mathrm{mg} / \mathrm{d}$ if possible

1. Decrease amitriptyline to $50 \mathrm{mg}$ at bedtime for $1 \mathrm{wk}$, then to $25 \mathrm{mg}$ for $2 \mathrm{wk}$, then stop if possible

2. Decrease cyclobenzaprine to twice daily (morning and bedtime); reduce frequency further if possible or reduce dose to $2.5 \mathrm{mg}$; eventually stop if possible (note: patient finds this medication most effective for pain control, so may be hardest to taper)

3. Re-evaluate usefulness of morphine and taper or stop if possible

4. Consider tapering carbamazepine to $100 \mathrm{mg}$ twice daily and eventually stopping

5. Once effect of above changes assessed, begin tapering oxazepam

1. See above for recommendations to reduce anticholinergic load, and for tapering morphine and diltiazem

2. Consider reassessing need for galantamine once above medication changes are made
Monitoring (team)

- Resolution of orthostatic hypotension

- Angina/use of nitroglycerin as needed

- Blood pressure target: $120 / 65 \mathrm{~mm} \mathrm{Hg}$ to $140 / 90 \mathrm{~mm} \mathrm{Hg}$

- Decrease in falls

- Improvement in renal function: repeat serum creatinine once quinapril dose reduced

- Sleep initiation

- Pain control

- Resolution of orthostatic hypotension

- Decrease in excessive sedation

- Improvement in balance, decrease in falls

- Seizure control

- Thyroid-stimulating hormone levels (decrease in carbamazepine may alter levothyroxine requirements)

Forgetfulness, difficulty finding words, apraxia

1. See above for recommendations to reduce anticholinergic load, and for tapering morphine and diltiazem

2. Stop lactulose, fibre supplement, bisacodyl and suppository

3. Start polyethylene glycol $3350,15 \mathrm{~mL}$ in water daily

Stop magnesium
Reduced straining

Consider checking magnesium level
Risk of bradycardia, atrioventricular block

- May be contributed to by combined use of acebutolol and diltiazem

Omeprazole: ongoing need unclear (duodenal ulcer several years ago but no heartburn)

1. Consider further tapering of acebutolol and possible discontinuation (as above)

2. Consider reducing diltiazem ER dose (as above) also or instead of step 1

1. Stop omeprazole and start rabeprazole $10 \mathrm{mg} / \mathrm{d}$ (least expensive proton pump inhibitor on provincial drug formulary) for $2 \mathrm{wk}$, then stop

2. Use calcium carbonate or alginate or low-dose ranitidine as needed for rebound heartburn

Rosuvastatin: not needed twice daily given potency and half-life

Salbutamol: not needed if no shortness of breath and not being used

Levofloxacin: taken daily, but prescribed only for 10 days more than a month ago

Concomitant amitriptyline and levofloxacin use: can cause prolonged QT interval

Glucosamine: benefit unlikely given questionable efficacy in osteoarthritis pain control and low dose (doses of $1.5 \mathrm{~g} / \mathrm{d}$ in clinical trials) ${ }^{3}$

Patient at increased risk of falls but is not receiving prophylaxis for osteoporosis
1. Reduce rosuvastatin to $20 \mathrm{mg}$ once daily

2. Consider requesting cholesterol levels from nursing home to confirm whether patient is at LDL target

Stop salbutamol

Stop levofloxacin

1. Taper and stop amitriptyline as suggested

2. Stop levofloxacin

Stop glucosamine

1. Start vitamin D $1000 \mathrm{IU} / \mathrm{d}$

2. Once constipation has resolved, start elemental calcium $500 \mathrm{mg}$ twice daily (review options with patient)

3. Consider bone density scan and bisphosphonate if indicated and if renal function improves
- Heart rate

- Angina

Rebound heartburn for 2-4 wk

Shortness of breath

Note: $\mathrm{CNS}=$ central nervous system, ER = extended release, $\mathrm{LDL}=$ low-density lipoprotein. 


\section{Box 3: Medication schedule at discharge}

\section{In the morning}

- Quinapril $40 \mathrm{mg}$

- Diltiazem ER $360 \mathrm{mg}$

- Furosemide $10 \mathrm{mg}$

- Levothyroxine $0.088 \mathrm{mg}$

- Tiotropium $18 \mu \mathrm{g}$

- Dipyridamole/ASA 200/25 mg

- Galantamine ER 16 mg

- Cranberry complex 500 mg

- Polyethylene glycol $335015 \mathrm{~mL}$

- Vitamin D 1000 IU

\section{At supper}

- Dipyridamole/ASA 200/25 mg

- Cranberry complex 500 mg

\section{At bedtime}

- Cyclobenzaprine $5 \mathrm{mg}$

- Oxazepam $15 \mathrm{mg}$

- Cranberry complex 500 mg

- Rosuvastatin $20 \mathrm{mg}$

- Carbamazepine $100 \mathrm{mg}$

\section{As needed}

- Nitroglycerin spray $0.4 \mathrm{mg} / \mathrm{spray}$

- Acetaminophen $650 \mathrm{mg}$

- Saliva substitute

Note: $A S A=$ acetylsalicylic acid, ER = extended release. anticonvulsants and opioids are known to cause excessive central nervous system (CNS) depression and increase the risk of falls in older people. The substantial sedation that may have been a result of additive CNS depressant effects made assessment of the patient's cognition challenging.

Keeping in mind the importance of finding the lowest effective dose of any medication being used, we reduced the patient's cyclobenzaprine dose and, when anxiety increased following cessation of carbamazepine, reinstated that drug at a small dose. This led us to suspect that the original indication might have been bipolar disorder, not post-seizure prophylaxis; however, we had difficulty assessing this without documentation from the original prescriber. Arrangements were made for follow-up with a geriatric psychiatrist after discharge. Amitriptyline was tapered and stopped; morphine was also stopped following interventions to help the patient cope with pain. Recommendations were made to the patient's family physician to continue with the oxazepam tapering following discharge from the day hospital.

\section{Multiple cardiovascular agents}

Given our patient's low blood pressure and orthostatic hypotension, as well as the likely contribution of several of the cardiovascular medications to recurrent falls, we stopped the nitroglycerin patch and amlodipine and reduced the furosemide dose. Given the increased risk of

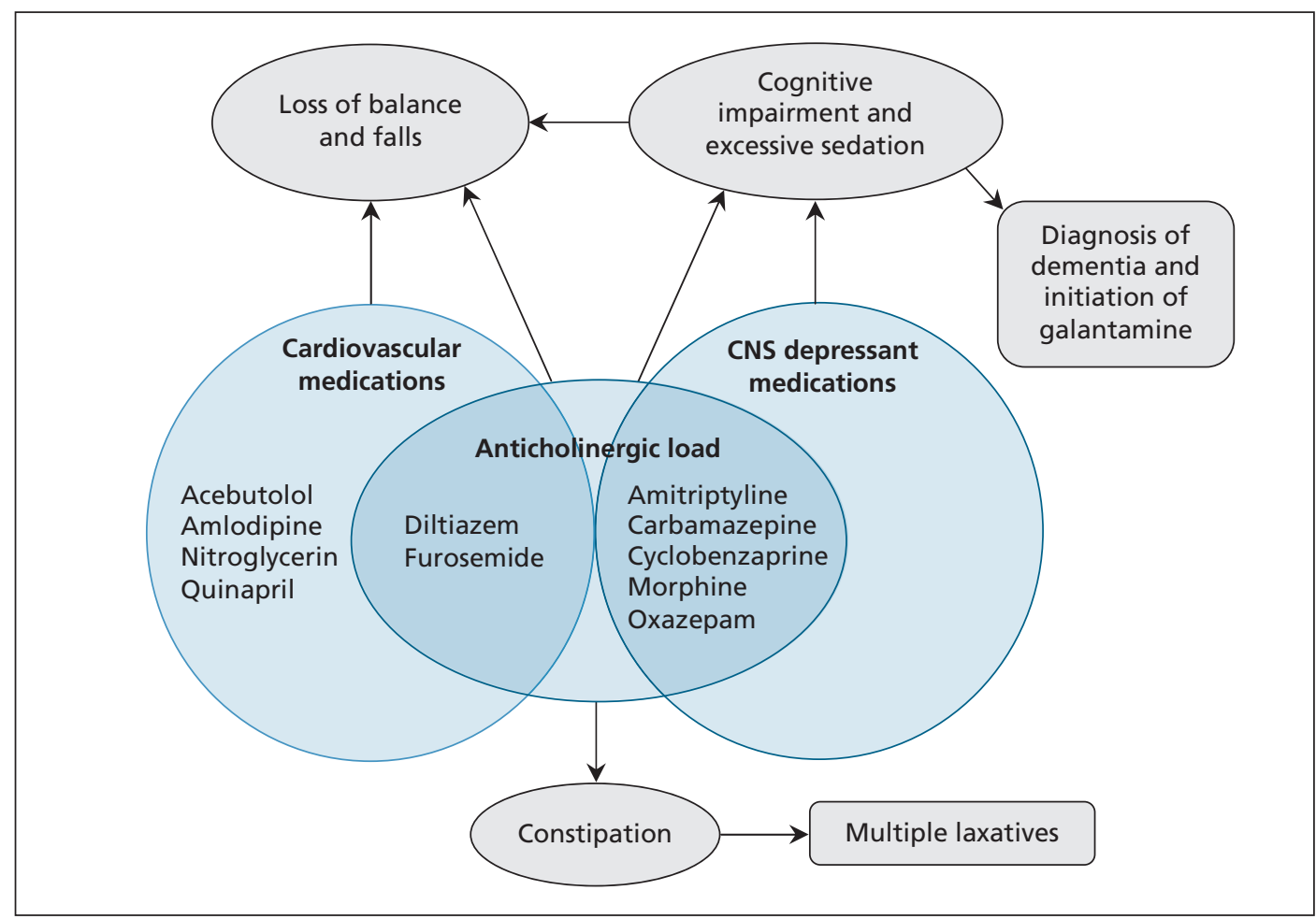

Figure 1: Interplay between the medications of a 77-year-old woman referred to a geriatric day hospital and their possible effects on sedation, cognition, constipation and risk of falls. CNS = central nervous system. 
acebutolol accumulation in older patients (3-fold increase in bioavailability and reduced renal excretion $)^{14}$ as well as the drug's potential to cause bradycardia and atrioventricular block when taken in combination with diltiazem, the dose of acebutolol was tapered and stopped. No rebound angina or tachycardia was reported during twice-weekly monitoring. The achieved target was a blood pressure in the range of 120/65 to $140 / 90 \mathrm{~mm} \mathrm{Hg}$, with the lower limit established because of the patient's level of frailty and coronary artery disease..$^{15}$ The patient was also able to consistently implement strategies to manage orthostatic hypotension that were taught to her by the nurse.

\section{Other problems}

We identified medications with no clear indication and those being used with questionable efficacy. For example, the patient had been taking omeprazole following remote duodenal ulcer but had no ongoing symptoms; discontinuation of the drug did not result in rebound heartburn. Administration of levofloxacin beyond 10 days may have been due to a transcription error; we notified the pharmacy to stop the medication. The salbutamol had not been used recently, which enabled us to stop it.

Poor adherence with laxative use likely contributed to the patient's continued problems with constipation. The patient demonstrated a poor understanding of proper laxative use but also had a complex medication regimen and cognitive difficulties, all of which have been shown to contribute to poor adherence. ${ }^{16}$ Drug-induced constipation and poor adherence to laxative therapy meant several laxatives were started, which contributed further to the pill burden. Regular doses of magnesium hydroxide in this setting of impaired renal function increased the risk of accumulation and toxicity. Several anticholinergic medications were stopped, along with all 5 laxatives. Polyethylene glycol 3350 at a dose of $15 \mathrm{~mL}$ once daily was started and resolved the constipation in about 1 week. The rosuvastatin dosage was simplified to once daily to reduce

\section{Resources for clinicians}

- A practical guide to stopping medicines in older people: www.bpac.org.nz/magazine /2010/april/stopGuide.asp

- Lee M, Jensen B, Regier L. Anticholinergics: reference list of drugs with anticholinergic effects. In: RxFiles drug comparison charts. 9th ed. Saskatoon (SK): Saskatoon Health Region; 2012.

- Kwan D, Farrell B. Polypharmacy — optimizing medication use in elderly patients. Pharmacy Practice 2012;29(2):20-5. pill burden. Vitamin D was added to reduce the risk of falls and maintain bone strength. ${ }^{17}$

A medication chart with indications for each medication and the reasons for stopping or lowering doses of others was provided. The patient and family were educated regarding the use of this chart as a central tool to assist all her prescribers in understanding how their medication changes could affect the patient's care. A final copy was sent to the patient's family physician with the discharge summary.

\section{Conclusion}

Polypharmacy is common among older patients. Several medications can be prescribed by different health care providers without assessment of the individual or additive impact of each drug on the overall function and well-being of the patient, or the ongoing need for each drug. In the case of our patient, several drugs caused or contributed to additive CNS depression, falls, cognitive difficulties and excessive sedation. An assessment of her medications for indication, effectiveness, safety and compliance identified drug-related contributors and allowed us to reduce her pill burden while optimizing her function and quality of life.

The close collaboration of the interprofessional health care team was instrumental. Interventions by different team members enabled subsequent medication changes, and medication changes facilitated additional interventions. Moreover, twice-weekly visits to a single location allowed the patient to receive close monitoring and ongoing support and to benefit from meaningful social interactions with her peers. Ultimately, an admission to a long-term care facility was no longer considered.

\section{References}

1. Cipolle RD, Strand LM, Morley PC, editors. Pharmaceutical care practice: the clinician's guide. New York (NY): McGrawHill; 2004.

2. Winslade N, Bajcar J. Therapeutic thought process algorithm. Ottawa $(\mathrm{ON})$ : National Association of Pharmacy Regulatory Authorities; 2009. Available: www.napra.org/Content_Files /Files/algorithm.pdf (accessed 2012 Oct 10)

3. Towheed TE, Maxwell L, Anastassiades TP, et al. Glucosamine therapy for treating osteoarthritis [review]. Cochrane Database Syst Rev 2005;(2):CD002946.

4. Anthierens S, Tansens A, Petrovic M, et al. Qualitative insights into general practitioners views on polypharmacy. BMC Fam Pract 2010;11:65.

5. Tune LE. Anticholinergic effects of medication in elderly patients. J Clin Psychiatry 2001;62(Suppl 21):11-4.

6. Ancelin ML, Artero S, Portet F, et al. Non-degenerative mild cognitive impairment in elderly people and use of anticholinergic drugs: longitudinal cohort study. BMJ 2006;332:455-9.

7. Rudolph JL, Salow MJ, Angelini MC, et al. The anticholinergic risk scale and anticholinergic adverse effects in older persons. Arch Intern Med 2008;168:508-13.

8. Mintzer J, Burns A. Anticholinergic side-effects of drugs in elderly people. J R Soc Med 2000;93:457-62.

9. Carrière I, Fourrier-Reglat A, Dartigues JF, et al. Drugs with anticholinergic properties, cognitive decline, and dementia in an elderly general population: the 3-city study. Arch Intern Med 2009; 169:1317-24. 
10. Pasina L, Djade CD, Lucca U, et al. Association of anticholinergic burden with cognitive and functional status in a cohort of hospitalized elderly: comparison of the anticholinergic cognitive burden scale and anticholinergic risk scale: results from the REPOSI Study. Drugs Aging 2013;30:103-12.

11. Shi X, Wray DW, Formes KJ, et al. Orthostatic hypotension in aging humans. Am J Physiol Heart Circ Physiol 2000;279:H1548-54.

12. Hutchison LC, O'Brien CE. Changes in pharmacokinetics and pharmacodynamics in the elderly patient. J Pharm Pract 2007;1:4-12.

13. Lee M, Jensen B, Regier L. Anticholinergics: reference list of drugs with anticholinergic effects. In: RxFiles drug comparison charts. 9th ed. Saskatoon (SK): Saskatoon Health Region; 2012.

14. Roux A, Henry JF, Fouache Y, et al. A pharmacokinetic study of acebutolol in aged subjects as compared to young subjects. Gerontology 1983;29:202-8.

15. Messerli FH, Mancia G, Conti CR, et al. Dogma disputed: Can aggressively lowering blood pressure in hypertensive patients with coronary artery disease be dangerous? Ann Intern Med 2006;144:884

16. Gellad WF, Grenard JL, Marcum ZA. A systematic review of barriers to medication adherence in the elderly: looking beyond cost and regimen complexity. Am J Geriatr Pharmacother 2011;9:11-23.

17. Bischoff-Ferrari HA, Dawson-Hughes B, Staehelin HB, et al. Fall prevention with supplemental and active forms of vitamin D: a meta-analysis of randomised controlled trials. BMJ 2009;339:b3692.

Competing interests: Barbara Farrell received an honorarium from the journal Pharmacy Practice for an article on polypharmacy; she also received an honorarium from RxFiles for preparing and presenting workshops on the management of polypharmacy. No competing interests declared by Véronique French Merkley or Wade Thompson.

Affiliations: Geriatric Day Hospital of Bruyère Continuing Care (Farrell, French Merkley, Thompson), Ottawa, Ont.; C.T. Lamont Primary Health Care Research Centre (Farrell), Bruyère Research Institute, Ottawa, Ont.; Department of Family Medicine (Farrell, French Merkley), University of Ottawa, Ottawa, Ont.; School of Pharmacy (Thompson), University of Waterloo, Waterloo, Ont.

Contributors: Barbara Farrell and Véronique French Merkley were the clinicians involved in the care of the patient. Wade Thompson prepared the initial draft of the manuscript and conducted relevant literature searches. All of the authors revised the manuscript critically for important intellectual content and approved the final version submitted for publication.

An expanded version of this article is available as a tool to teach about interprofessional approaches to the management of polypharmacy (see Appendix 3, available at www.cmaj.ca/lookup/suppl/doi:10.1503/cmaj.122012/-/DC1).

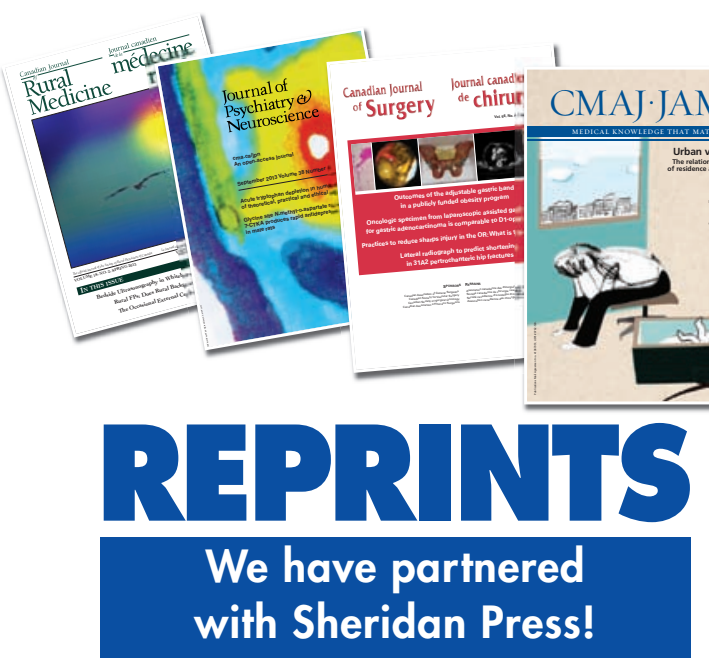

To purchase commercial article reprints and e-prints or to request a quote, please contact

\section{Matt Neiderer}

Content Sales

Sheridan Content Services

$800635-7181 \times 8265$

matt.neiderer@sheridan.com
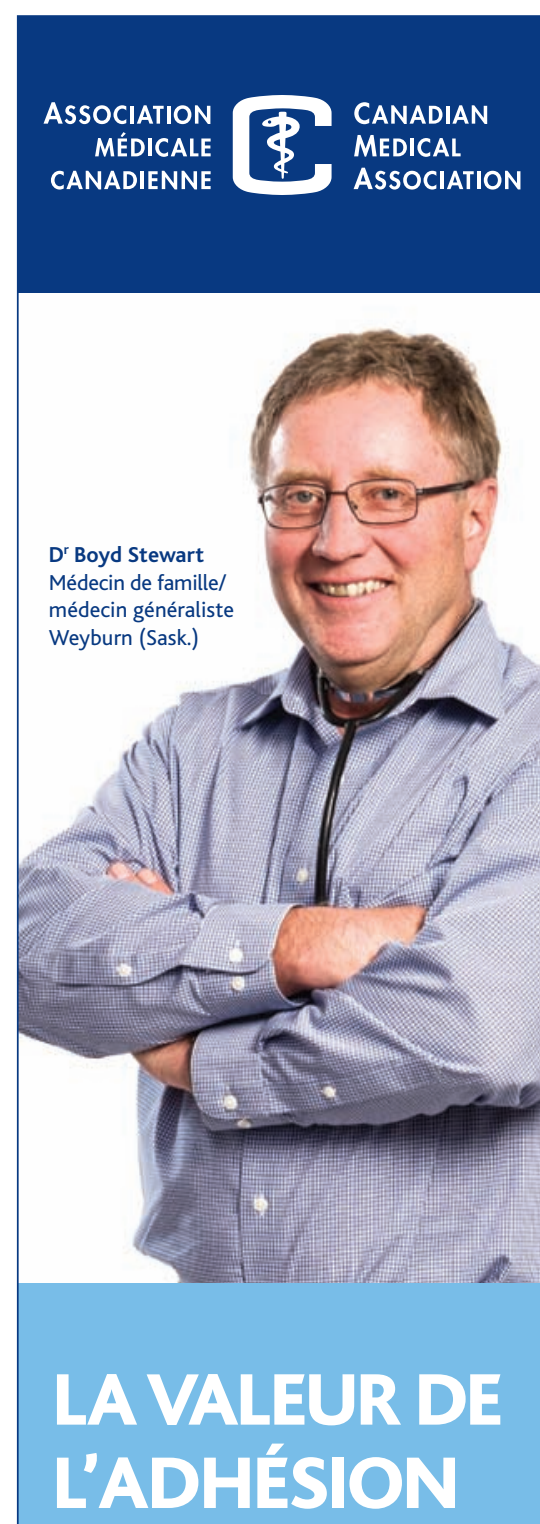

- Solutions de gestion globale du patrimoine

- Ressources et outils cliniques en ligne

- JAMC

- Représentation et promotion

Pour connaître tous les avantages de l'adhésion, composer le 888-855-2555 ou consulter amc.ca/membres 